\title{
Protein glycosylation in cancers and its potential therapeutic applications in neuroblastoma
}

\author{
Wan-Ling Ho ${ }^{1,2,3}$, Wen-Ming Hsu ${ }^{4,5^{*}+}$, Min-Chuan Huang ${ }^{5,6^{*+}}$, Kenji Kadomatsu ${ }^{7}$ and Akira Nakagawara ${ }^{8}$
}

\begin{abstract}
Glycosylation is the most complex post-translational modification of proteins. Altered glycans on the tumor- and host-cell surface and in the tumor microenvironment have been identified to mediate critical events in cancer pathogenesis and progression. Tumor-associated glycan changes comprise increased branching of N-glycans, higher density of O-glycans, generation of truncated versions of normal counterparts, and generation of unusual forms of terminal structures arising from sialylation and fucosylation. The functional role of tumor-associated glycans ( $T n, s T n, T$, and $s L e^{a / x}$ ) is dependent on the interaction with lectins. Lectins are expressed on the surface of immune cells and endothelial cells or exist as extracellular matrix proteins and soluble adhesion molecules.

Expression of tumor-associated glycans is involved in the dysregulation of glycogenes, which mainly comprise glycosyltransferases and glycosidases. Furthermore, genetic and epigenetic mechanisms on many glycogenes are associated with malignant transformation. With better understanding of all aspects of cancer-cell glycomics, many tumor-associated glycans have been utilized for diagnostic, prognostic, and therapeutic purposes. Glycan-based therapeutics has been applied to cancers from breast, lung, gastrointestinal system, melanomas, and lymphomas but rarely to neuroblastomas (NBs). The success of anti-disialoganglioside (GD2, a glycolipid antigen) antibodies sheds light on glycan-based therapies for NB and also suggests the possibility of protein glycosylation-based therapies for NB. This review summarizes our understanding of cancer glycobiology with a focus of how protein glycosylation and associated glycosyltransferases affect cellular behaviors and treatment outcome of various cancers, especially NB. Finally, we highlight potential applications of glycosylation in drug and cancer vaccine development for NB.
\end{abstract}

Keywords: Cancer, Glycan-based therapeutics, Glycosyltransferase, Lectin, Neuroblastoma, Protein glycosylation, Treatment

\section{Background}

Glycosylation is the most complex post-translational modification of proteins and is involved in many physiological events, such as host-pathogen interaction, cell differentiation and trafficking, and intracellular and intercellular signaling. Tumor-associated glycan changes comprise increased branching of $\mathrm{N}$-glycans, higher density of $\mathrm{O}$-glycans, generation of truncated versions of normal

\footnotetext{
* Correspondence: billwmhsu@gmail.com; mchuang@ntu.edu.tw

tEqual contributors

${ }^{4}$ Department of Surgery, National Taiwan University Hospital, 7 Chung-Shan South Road, Taipei 100, Taiwan

${ }^{5}$ Research Center for Developmental Biology and Regenerative Medicine, National Taiwan University, Taipei, Taiwan

Full list of author information is available at the end of the article
}

counterparts (Tn, sTn, and T antigens), and generation of unusual forms of terminal structures with sialic acid and fucose (sLe $\mathrm{a}^{\mathrm{a}}$ and $\mathrm{sLe}^{\mathrm{x}}$ epitopes), mainly caused by the genetic and epigenetic desregulation of glycogenes and the tumor microenvironment. Changes in oligosaccharide structures of glycoproteins or glycolipids are involved in cancer progression through the dysregulation of cell cycle, promotion of cell proliferation and growth, degradation of the extracellular matrix (ECM) and basement membranes, promotion of tumor dissemination and angiogenesis, and facilitation of immune evasion [1]. A massive potential for glycan diversity exists; however, a limited range of glycans are associated with invasion and metastatic potential in various tumors [1]. The endogenous animal lectins 
(glycan-binding proteins) participate in fundamental processes such as quality control of secreted proteins, host-pathogen recognition, cell adhesion, and motility. The interactions of lectins with tumor-associated glycans facilitate tumor progression in lung cancers, colon cancers, pancreatic carcinomas, melanomas, and neuroblastomas (NBs) [2-6].

$\mathrm{NB}$ is the most common extracranial solid tumor in children and the most common solid tumor of infancy, accounting for about 8-10\% of childhood cancers and for about $15 \%$ of cancer deaths in children. The median age of children at diagnosis is 22 months, and $90 \%$ of cases are diagnosed by 5 years of age. The annual incidence is estimated to be about 1/70,000 in children under the age of 15 [7]. There are $~ 150$ new cases diagnosed each year in Japan and 30 40 new cases diagnosed each year in Taiwan according to the Japan Neuroblastoma Study Group and the Registry of Childhood Cancer Foundation of Taiwan, respectively $[8,9]$. NB is a genetically and clinically heterogeneous cancer arising from embryonal sympathetic nervous system, exhibiting from spontaneous differentiation or regression with a favorable prognosis to highly undifferentiated tumors with rapid progression and very poor outcomes [7]. Although the overall prognosis of NB patients has improved remarkably with recent therapeutic advances, long-term survival of aggressive forms of NB remains poor even with intensive multimodal therapy [7]. The Children's Oncology Group stratified patients into low-, intermediate-, or high-risk groups based on age at diagnosis, International Neuroblastoma Staging System (INSS) stage [10], tumor histology, DNA index (ploidy), and MYCN (V-myc myelocytomatosis viral-related oncogene) amplification status [11]. The osteomedullary recurrences from residual disease often result in treatment failure; in addition, the NB patients in either intermediateor high-risk group present with prognostic heterogeneity. It is therefore important to identify more useful cancer biomarkers which allow for subgrouping NB patients as homogeneously as possible in terms of biology and outcome. Glycan-based therapeutics has been applied to cancers from breast, lung, gastrointestinal system, melanomas, and lymphomas but rarely to NBs [12-19]. In NB, disialoganglioside (GD2; a surface glycolipid synthesized by GD2 synthase) is uniformly expressed by virtually all neuroblasts and facilitates the attachment of NB cells to ECM [20]. This feature makes GD2 a potential molecular marker for residual disease detection and a target for immunotherapy. The success of anti-GD2 antibodies suggests that glycanbased therapies may be effective in patients with high-risk NB. Researchers have also envisaged the possibility of using protein glycosylation-based therapies to treat NB.

This review summarizes our understanding of cancer glycobiology and focuses on how protein glycosylation affects the cellular behavior and treatment outcomes of various cancers, especially NB. The effects exerted by glycosyltransferases, tumor cell-cell, and tumor cellECM interactions are also elucidated. Finally, this review discusses the advances in glycan-based therapies that have been utilized for a variety of cancers, such as glycosyltransferase inhibitors, glycomimetics, and glycanbased vaccines/immunotherapies. It is anticipated that NB-associated glycoforms regulated by genetic and epigenetic machinery will provide information with which novel therapeutic targets can be identified, and new therapies can be developed.

\section{Protein glycosylation in normal and malignant cells}

$\mathrm{N}$ - and $\mathrm{O}$-glycosylation of proteins

Glycans are expressed in several types of glycoconjugates, namely glycoproteins, glycosphingolipids, proteoglycans/glycosaminoglycans (GAGs), and glycosylphosphatidylinositol (GPI)-linked proteins. During protein synthesis, glycans assure correct folding in the endoplasmic reticulum (ER) and are involved in trafficking of newly synthesized proteins [21]. They also protect proteins from degradation inside or outside the cell by means of interfering with proteolysis. Many glycans act as receptors for bacteria, viruses, and other pathogens. The cell-surface sugar structures allow the immune cells to differentiate self/normal cells from nonself/abnormal cells. They are also involved in cell-cell and cell-matrix interactions which are associated with cancercell invasion to the surrounding tissue or extravasation to form metastatic lesions [22].

There are two major types of protein glycosylation in mammalian cells, namely $N$-linked and $O$-linked. Both types often coexist in the same protein. The synthesis of $\mathrm{N}$-glycans is initiated in the ER by transfer of a preformed lipid (dolichopyrophosphate)-linked oligosaccharide precursor containing three glucoses, nine mannoses, and two $N$-acetylglucosamines, written as $(\mathrm{GlC})_{3}(\mathrm{Man})_{9}(\mathrm{GlcNAc})_{2}$, to asparagine of nascent proteins. Subsequent processing occurs in the ER for protein folding, including cycles of glucose removal and addition. $\mathrm{N}$-glycan chains can be further diversified in the Golgi apparatus as well [23]. N-glycans can be divided into three types according to the sugar moiety structures: high-mannose type, hybrid type, and complex type (Fig. 1). O-glycans are synthesized in the ER, Golgi apparatus, or cytosol by stepwise enzyme transfer of monosaccharides without the need of dolichol carrier. The frequency of $O$-glycosylation on many glycoproteins is high, especially on secreted or membrane-bound mucins, which are rich in serine and threonine. Mucintype $\mathrm{O}$-glycosylation which is the most common type of $O$-glycosylation in mammals is highly conserved in the evolutional course of many species; it is initiated by the transfer of $\mathrm{N}$-acetylgalactosamine (GalNAc) to a serine 


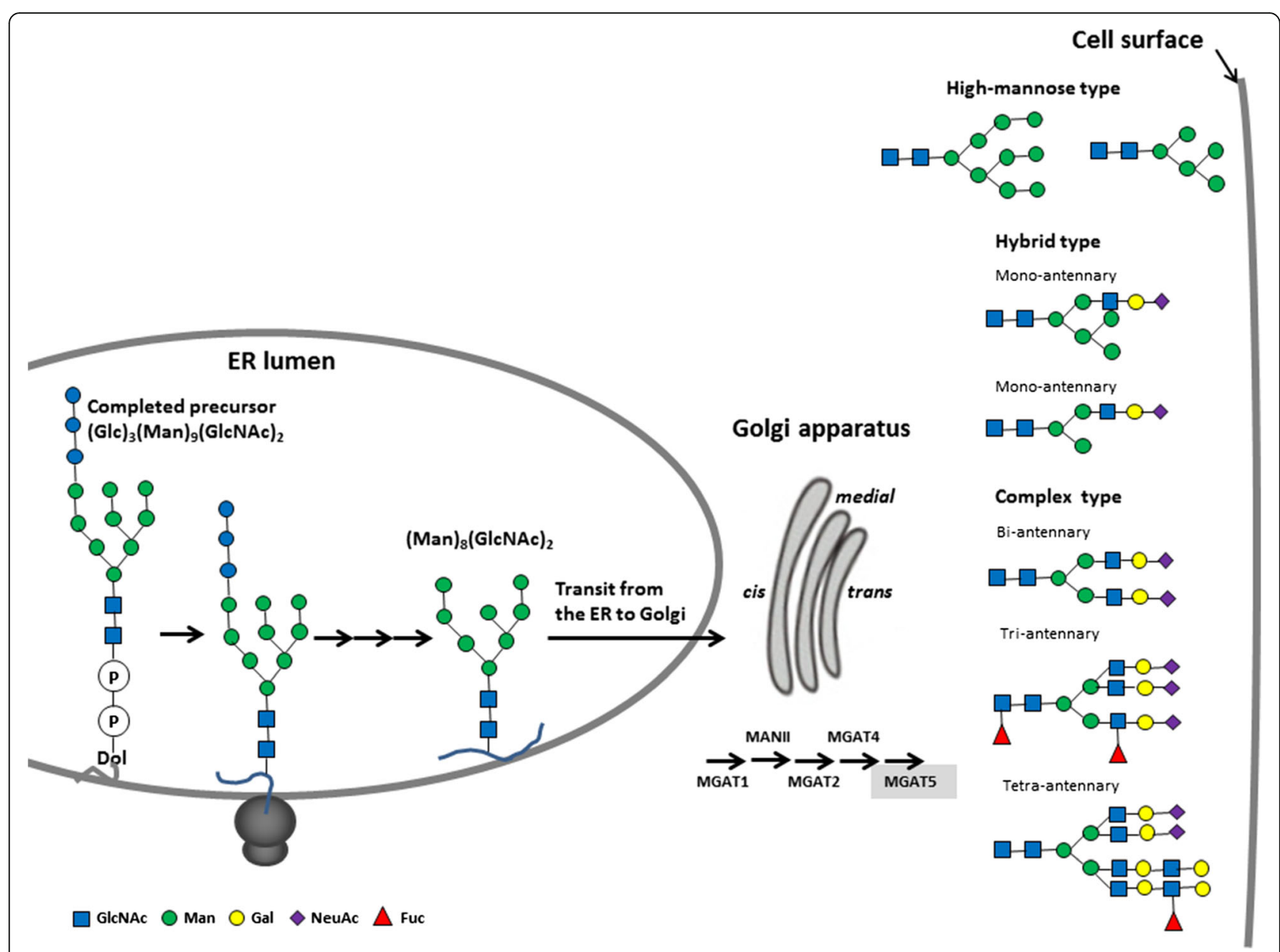

Fig. 1 An overview of the process of $\mathrm{N}$-glycosylation. Glycosyltransferases involved in the synthesis are indicated. Additional modifications exist (not shown). Dol dolichopyrophosphate, MGAT $\beta 1,6-N$-acetylglucosaminyltransferase, MANII mannosidase II, GlcNAc N-acetylglucosamine, Man mannose, Gal galactose, NeuAc N-acetylneuraminic acid, Fuc fucose. Glycosyltransferases shown in Table 1 are highlighted, except B4GALNT3

or threonine residue, thereby forming the Thomsennouvelle antigen ( $\mathrm{Tn} \mathrm{Ag}$ ) (Fig. 2) [24]. This reaction is catalyzed by a family of polypeptide GalNAc transferases (GALNTs) that consists of at least 20 members in humans, namely GALNT1 to 20 [25]. T synthase (or core $1 \beta 1,3$-galactosyltransferase (C1GALT1)) galactosylates $\mathrm{Tn}$ to form the core 1 (Gal $\beta 1 \rightarrow 3$ GalNAc, $\mathrm{T}$ antigen) [26]. Core 2 is formed by adding a branching GlcNAc to core 1 by core $2 \beta 1,6-N$-acetylglucosaminyltransferases (GCNTs 1, 3, and 4) [27]. Alternatively to the core 1 structure formation, GlcNAc instead of Gal can be transferred in a $\beta 1-3$ linkage forming the core 3 structure by $\beta 1,3-N$-acetylglucosaminyltransferase 6 (B3GNT6) [28]. Core 3 may serve as an acceptor substrate for the core 4 enzyme, GCNT3, which adds GlcNAc in a $\beta 1-6$ linkage to GalNAc (Fig. 2). Core structures 5-8 have an extremely restricted occurrence, and core 7 has not been found in humans [29]. Other non-mucin-type $O$-glycosylations are not further discussed in this review.

\section{Lectins (glycan-binding proteins)}

Three main types of lectins, namely siglecs, galectins, and selectins, are glycan-binding proteins (GBPs) that are highly specific for sugar moieties. In healthy organisms, various endogenous lectins are associated with fundamental processes such as cell-cell recognition, cell adhesion and motility, and pathogen-host recognition. Many lectins are expressed on the surface of immune cells and endothelial cells or exist as ECM proteins and soluble adhesion molecules [1]. Siglecs are sialic acid-binding immunoglobulinlike lectins, which are expressed on specific subpopulations of hematopoietic cells such as macrophages, natural killer cells, and B cells. The binding of siglecs to tumor-derived glycans may exert various immune activities leading to anti-tumor immunity or tumor escape of immune surveillance [5]. The galectin family consists of 15 members, which are expressed by various cell types including epithelial and immune cells. Galectins belong to soluble (different from the membrane-bound nature for siglecs and selectins) immunomodulatory lectins and bind to galactose 


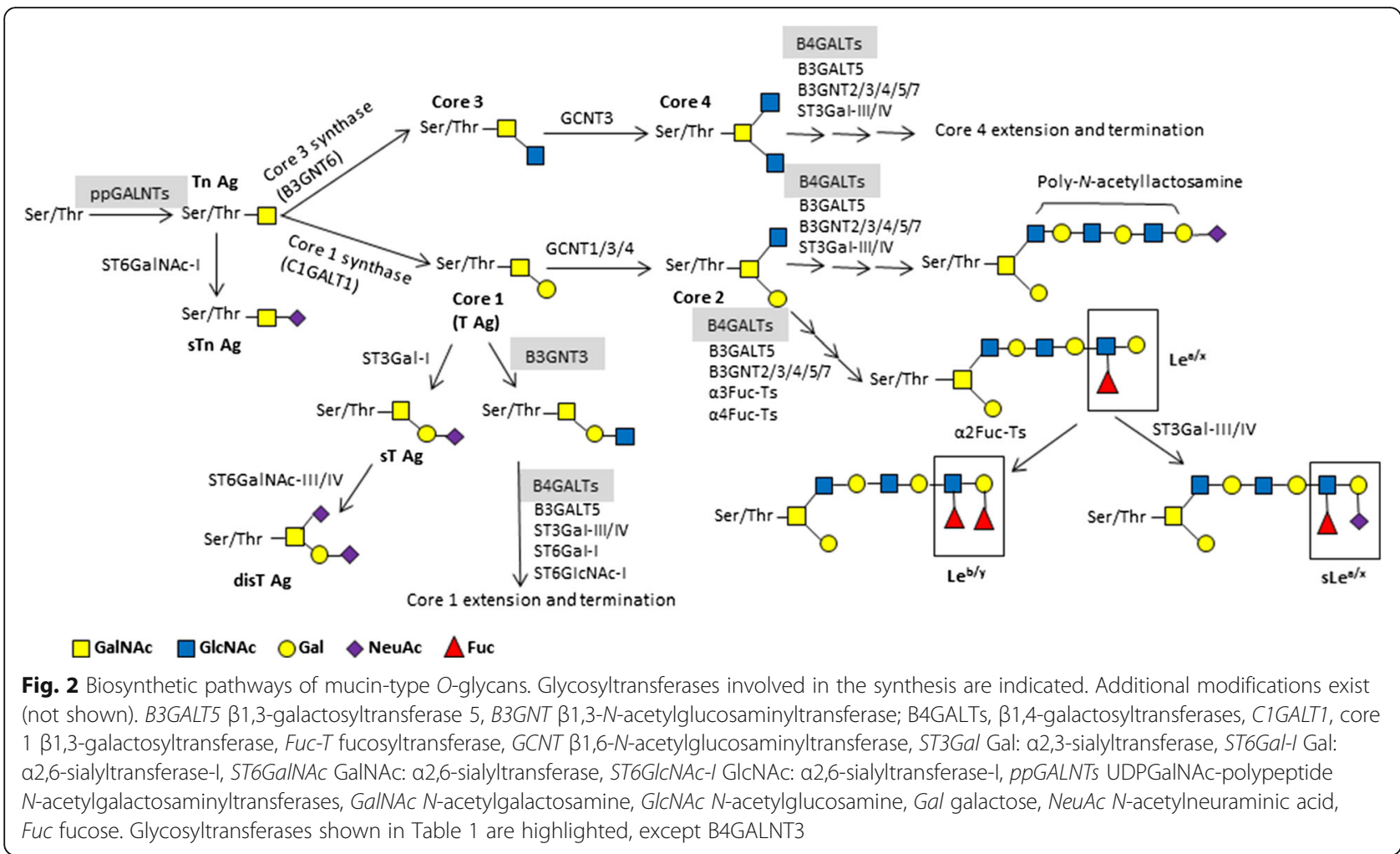

that is either $\beta 1,3$ or $\beta 1,4$-linked to $N$-acetylglucosamine at the cell surface, forming lattices that fine-tune the dynamics of receptor-ligand interactions. Accumulating evidence indicates that cancer-associated galectins facilitate invasive phenotype of tumor cells [30]. The selectin family consists of L-, E-, and P-selectin, which share $\sim 50 \%$ sequence homology in the C-type lectin domain. Their ligands typically consist of glycans capped with sialic acid, fucose, and sulfate. Selectins normally mediate adhesion of platelets (which express P-selectins), homing and development of leukocytes/lymphocytes (which express L-selectins), and recruitment of immune cells in response to inflammation (E- and P-selectins). The interactions between lectins and tumor cell-derived glycans alter tumor cell-cell interaction and cell-ECM adhesion, thereby facilitating tumor progression/dissemination [1].

\section{Altered protein glycosylation in cancers}

Altered glycosylation of membrane-bound (such as cytokine or growth factor receptors, integrins, and cadherins) and secreted glycoproteins is associated with various cancers $[31,32]$. Ogata et al. found that malignant cells are more enriched in highly branched complex-type $N$-linked sugar chains than their normal counterparts [33]. Many subsequent studies confirmed that an increase of $\beta 1-6$ branching of the complex-type $N$-linked sugar chains is associated with cancer growth and metastasis. $\beta 1,6-N$ acetylglucosaminyltransferase V (GnT-V; MGAT5) is one of the most relevant glycosyltransferases associated with cancer migration, invasion, and metastasis (Fig. 3). This enzyme is responsible for adding GlcNAc in a $\beta 1,6$-linkage, initiating the fourth branch in a sequential pathway to tetraantennary $N$-glycans (Figs. 1 and 3) [34]. In human breast and colorectal cancers, the expression of $\beta 1-6$ branched oligosaccharides regulated by GnT-V can serve as a marker for tumor progression, metastasis, and poor prognosis $[35,36]$. However, GnT-V may exhibit opposite effects on other neoplasms. For example, GnT-V expression predicts a favorable prognosis and treatment outcome in lung cancers and NB [37, 38]. On the other hand, GnT-III catalyzes the attachment of a GlcNAc to a core mannose of $N$-glycan via a $\beta 1,4$-linkage to form the bisecting GlcNAc structure and has been proposed to antagonize GnT-V, thereby contributing to the suppression of cancer metastasis [39].

Many mucin-type $O$-glycosyltransferases have been assigned biological functions, and aberrant expression of these enzymes is associated with human diseases. For example, the expression of $\mathrm{N}$-acetylgalactosaminyltransferase (GALNT) 3 is a potential diagnostic and prognostic marker for lung [40] and pancreatic [41] cancers. GALNT6 can glycosylate and stabilize oncoprotein mucin 1 (MUC1), thereby contributing to mammary carcinogenesis via disruption of cell adhesion molecules ( $\beta$-catenin and E-cadherin). The same research team also found that GALNT6fibronectin pathway is also a critical component for breast 


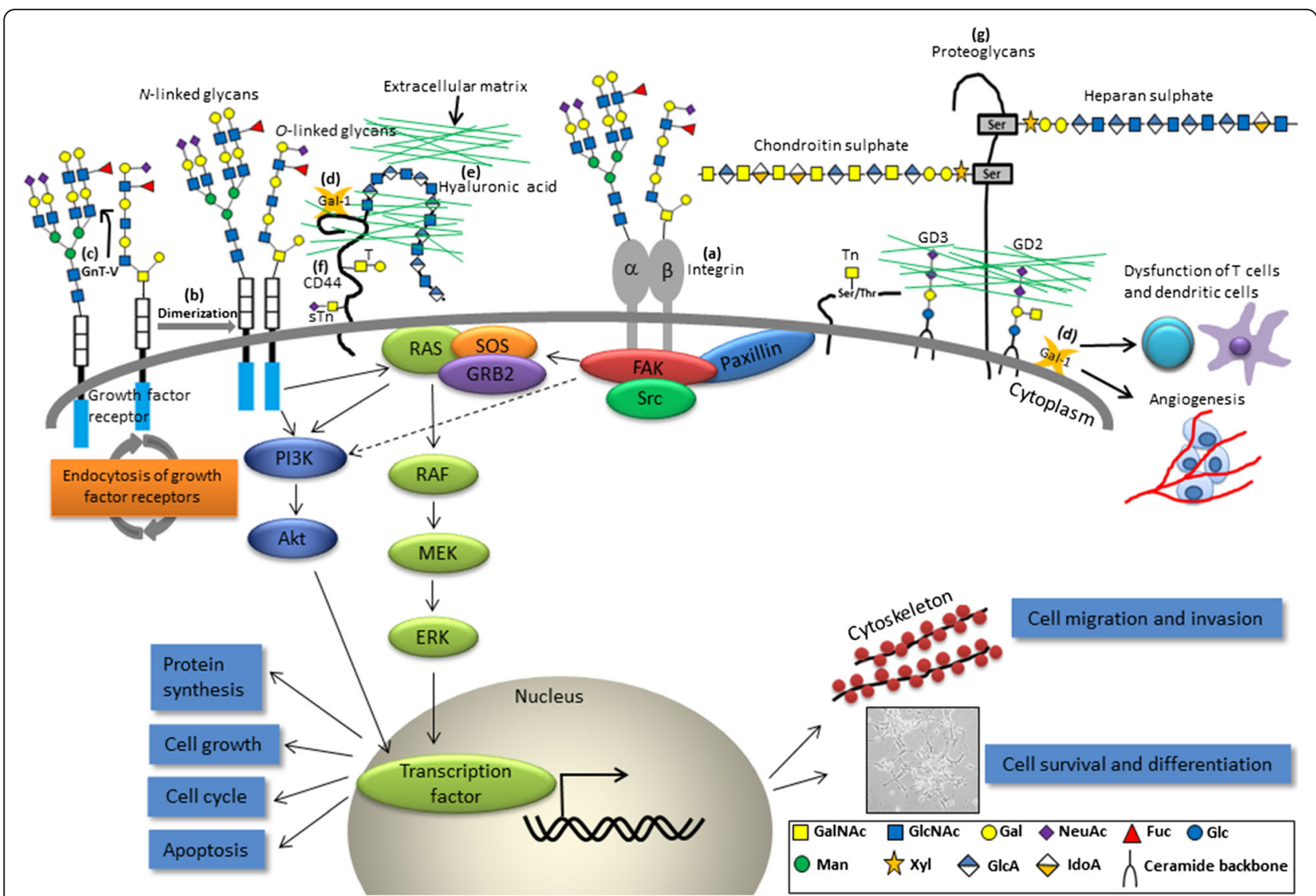

Fig. 3 Altered glycans and related pathophysiological events involved in NB progression. a $\beta 1,4-N$-acetylgalactosaminyltransferase 3 (B4GALNT3) and $\beta 1,4$-galactosyltransferase 3 (B4GALT3) exhibit differential effects on malignant phenotypes by modification of $\beta 1$ integrin in NB cells; $\mathbf{b}$ $\mathrm{N}$-acetylgalactosaminyltransferase 2 (GALNT2) modifies O-glycans on IGF-1R, thereby suppressing IGF-1-induced IGF-1R dimerization and downstream signaling; c N-acetylglucosaminyltransferase V (GnT-V) modulates the sensitivity of NB to apoptosis; $\mathbf{d}$ Gal-1 promotes attachment of NB cells to the extracellular matrix (ECM) and endothelial cells through binding to CD44. Besides, Gal-1 may dampen the function of T cells and dendritic cells as well. Glycosaminoglycans present as e free polysaccharides (hyaluronic acid), a major counterreceptor for $\mathbf{f}$ CD44, or $\mathbf{g}$ as part of proteoglycans (heparan sulfate and chondroitin sulfate). GalNAc N-acetylgalactosamine, GICNAC N-acetylglucosamine, Gal galactose, NeuAc, $\mathrm{N}$-acetylneuraminic acid, Fuc fucose, G/c glucose, Man mannose, Xyl xylose, GlcA glucuronic acid, IdoA iduronic acid

cancer development and progression [42, 43]. GALNT14 modulates death-receptor $\mathrm{O}$-glycosylation in pancreatic carcinoma, non-small-cell lung carcinoma, and melanoma cells, and may therefore serve as a predictive biomarker for Apo2L/tumor necrosis factor-related apoptosis-inducing ligand-based cancer therapy [44].

Increased expression of shorter $O$-glycan structures such as Thomsen-Friedenreich (T), Tn, sialyl-Tn (sTn), and common tumor-cell epitopes such as sialyl-Lewis A (sLe ${ }^{\mathrm{a}}$ ) and sialyl-Lewis $\mathrm{X}\left(\mathrm{sLe}^{\mathrm{x}}\right)$ has been observed in a number of carcinomas of several organs (such lung, colon, stomach, and pancreas) and is associated with malignant transformation, cancer growth, and metastatic ability [45-49]. Impaired function of glycosyltransferases responsible for the synthesis of core structures used as substrates of chain elongation and/or overexpression of sialyltransferases (such as sialyltransferases ST6GalNAc-I and ST3Gal-I) responsible for the synthesis of sTn and sT antigens may result in increased expression of incomplete glycan structures (Fig. 2) [50, 51]. The chaperone protein Cosmc is responsible for folding and stability of $\beta 1,3$-galactosyltransferase ( $\mathrm{T}$ synthase). Mutation in Cosmc chaperone leads to increased Tn and sTn expression in colon carcinoma and melanoma cells [52]. Mucins contain both $O$-linked and $\mathrm{N}$-linked oligosaccharides and are major carriers of these cancer-associated carbohydrates. Multiple mucin domains differentially interact and regulate different components of the tumor microenvironment [53].

\section{Altered lectin-glycan interactions in cancers}

The functional role of tumor-associated glycans has been noted to be dependent on lectin binding. Miyazaki et al. reported that non-malignant colon epithelial cells express di-sLe ${ }^{\mathrm{a}}$ and 6-sulfo sLe ${ }^{\mathrm{x}}$ which serve as ligands for siglec-7 and siglec- 9 on resident macrophages in the colonic lamina propriae. Expression of di-sLe ${ }^{\mathrm{a}}$ and 
6-sulfo sLe ${ }^{\mathrm{x}}$ was decreased during malignant transformation, and was replaced by increased expression of sLe $^{\mathrm{a}}$ and $\operatorname{sLe}^{\mathrm{x}}$ which have no siglec ligand activity. Meanwhile, they found that normal glycans of epithelial cells exert a suppressive effect on cyclooxygenase-2 expression by resident macrophages, thus maintaining immunological homeostasis in colonic mucosal membranes, whereas loss of immunosuppressive glycans by impaired glycosylation during colonic carcinogenesis enhances inflammatory damage of the colonic mucosa [5]. Galectins, another type of lectins, are versatile modulators of cancer growth and metastasis. Tumor-derived galectin-1 (Gal-1) induces tumor angiogenesis and promotion of immunosuppression by $\mathrm{T}$ cell apoptosis in several types of cancers, including melanomas, NB, lung cancers, and pancreatic carcinomas, therefore correlating with tumor aggressiveness and metastasis [3, 4]. Expression of the $\alpha 2,6$-sialyltransferase-1 (ST6Gal-I) specifically resulted in increased sialylation of $N$-glycans on $\mathrm{CD} 45$, a receptor tyrosine phosphatase of $\mathrm{T}$ cell receptor for Gal-1, thereby inhibiting Gal-1 binding activity and Gal-1-induced T cell death [54]. In addition, Gal-1 might also be involved in alteration of tumor cell-cell and cell-matrix interactions and formation of platelet-cancercell complexes [1]. N-glycans are the major ligands for galectin-3 at the cell surface [55]. Oncogenesis increases lectin-glycoprotein lattice by upregulating galectin-3 gene expression and higher-affinity $\mathrm{N}$-glycan ligands, which in turn enhances the availability of tyrosine kinase receptors for epidermal growth factor (EGF), transforming growth factor (TGF)- $\beta$, insulin-like growth factor (IGF) and platelet-derived growth factor (PDGF) in a ligand-sensitive state [56]. For all three selectins, the minimal recognition epitopes are $\mathrm{sLe}^{\mathrm{x} / \mathrm{a}}$ (Fig. 2) which are present on blood cells, certain vascular endothelial cells, and glycoconjugates of the tumor-cell surface. The most common mucins carrying selectin ligands that are associated with cancer dissemination are MUC1, MUC2, MUC4, and MUC16 [57-59]. Besides, other selectin ligands carriers on tumor cells include P-selectin glycoprotein ligand-1, CD24, CD44 (which carries T and sTn antigens) (Fig. 3) [60], death-receptor 3, E-selectin glycoprotein ligand-1 [61]. Selectin-mediated interactions facilitate metastatic seeding by increased vascular permeability, forming aggregates with platelets and leukocytes, and lodgment in the small vessels of distant organs [62].

\section{The impacts of altered protein glycosylation on NB}

\section{Altered $\mathrm{N}$ - and $\mathrm{O}$-glycans in NB}

$\mathrm{N}$-linked glycosylation is a highly regulated posttranslational modification, which is associated with many biological processes. It was found that the expression of intercellular adhesion molecule-2 (ICAM-2) suppresses tumor dissemination in a murine model of metastatic NB. Reduced $N$-glycosylated ICAM-2 by site-directed mutagenesis resulted in an attenuated ability to suppress metastasis of NB cells [63, 64]. Anaplastic lymphoma kinase (ALK) protein expression is up-regulated significantly in advanced/metastatic NB compared with localized NB, regardless the presence of mutated or wild-type ALK $[65,66]$. Inhibition of $N$-linked glycosylation by tunicamycin affects ALK phosphorylation and disrupts downstream pro-survival signaling in vitro, indicating that inhibition of this post-translational modification may be a promising therapeutic approach [67]. However, as tunicamycin is not a likely candidate for clinical use, future studies will assess whether the efficacy in inhibiting ALK activity might be enhanced by the combination of ALK specific small molecules [68,69] and $N$-linked glycosylation inhibitors.

While altered protein glycosylation is a hallmark of carcinomas, which express truncated $O$-glycans or sialylated versions of the normal counterparts at the cell surface (such as $\mathrm{Tn}, \mathrm{T}$, and sTn antigens), evidence suggests that mucintype $\mathrm{O}$-glycosyltransferases play an important role in NB biology, which is discussed further in the next section.

\section{The role of glycosyltransferases in NB}

Because aberrant expression of $\mathrm{N}$-glycans and short $\mathrm{O}$-glycans has been detected in human NB cells, and their expression levels are regulated by associated glycosyltransferases [70], many research groups have been looking for potential glycosyltransferases as markers for residual disease detection, risk group assignment, and the prognostic factor. The authors found that GnT-V expression predicted a favorable prognosis and treatment outcome in NB. Additionally, GnT-V knockdown in NB cells resulted in a decrease in retinoic acid-induced apoptosis accompanied by morphological changes [38]. Using oligomicroarray transcriptome analysis between primary tumor versus bone marrow metastatic cell lines, Berois et al. reported that GALNT13 may serve as an informative marker for the molecular diagnosis of bone marrow involvement and the follow-up of minimal residual disease (MRD) in NB patients [71]. By contrast, GALNT9 was expressed in neuroblasts derived from the primary tumor in the IGR-N91 NB model [72] but not in those derived from metastatic bone marrow and may serve as a prognostic marker for better clinical outcome in NB patients [73]. Over the past few years, our team had studied a series of glycosyltransferases which were reported to have prognostic impacts on $\mathrm{NB}$ in the public microarray datasets of Oncogenomics (https://pob.abcc.ncifcrf.gov/cgi-bin/JK). The expression status, clinical relevance, and functional role of these glycosyltransferases in NB as well as other cancers are discussed as follows. 


\section{$\beta 1,3-N$-acetylglucosaminyltransferase 3}

$\beta 1,3-N$-acetylglucosaminyltransferase 3 (B3GNT3) is responsible for adding GlcNAc to core 1 ( $\mathrm{T}$ antigen: $\mathrm{T} \mathrm{Ag}$ ) in a $\beta 1,3$-linkage, forming extended core 1 oligosaccharides (Fig. 2). B3GNT3 belongs to the $\beta 3$ GlcNAcT gene family, which consists of at least eight different $\beta 3$ GlcNAcTs [74]. B3GNT3 was identified for the first time to express in the high endothelial venules (HEVs) of secondary lymphoid organs; it contributes to the synthesis of HEV-borne L-selectin ligands and the lymphocyte homing [75]. B3GNT3 is also expressed in lymphocytes and neutrophils, involving in the biosynthesis of the backbone structure of $\mathrm{sLe}^{\mathrm{x} / \mathrm{a}}$, which plays a critical role in E-selectin adhesion [75, 76]. Genetic variation in B3GNT3 gene was correlated with the risk of non-Hodgkin lymphoma [76] and the CA19-9 plasma concentration (e.g., detection of $\mathrm{sLe}^{\mathrm{a}}$ epitope) [77]. However, our research team demonstrated that B3GNT3 expression examined using immunohistochemistry (IHC) correlates positively with the histological grade of differentiation as well as favorable Shimada histology and is an independent prognostic factor of better survival outcome for NB. Cell line experiments demonstrated that B3GNT3 expression decreases core 1 ( $\mathrm{T}$ antigen) as well as malignant phenotypes including migration and invasion (Table 1) [78].

\section{$\beta 1,4-N$-acetylgalactosaminyltransferase 3}

$\beta 1,4-N$-acetylgalactosaminyltransferase 3 (B4GALNT3) has been cloned, and its transcript is highly expressed in stomach, colon, and testis [79]. This enzyme can transfer GalNAc to any nonreducing terminal GlcNAc- $\beta$ in vitro, resulting in the synthesis of GalNAc $\beta 1,4 \mathrm{GlcNAc}$ (LacdiNAc or LDN). This special terminal $\beta 1,4$ GalNAc structure is found in certain glycoproteins and glycohormones; one of them is the sorting protein-related receptor SorLA/LR11 which shuttles between the plasma membrane, endosomes, and the Golgi. SorLA/LR11, highly expressed by neurons in the central and peripheral nervous systems, bears $N$-linked oligosaccharides modified with terminal $\beta 1$,4-linked GalNAc-4-SO $\mathrm{SO}_{4}$ that can be synthesized by B4GALNT3 in CHO cells [80]. By using IHC analysis to examine the B4GALNT3 expression in NB tumors, we found that B4GALNT3 expression correlates positively with the differentiation status of NB and early clinical stage (INSS stage 1,2, and 4S) and may predict a favorable prognosis independently. Cell line experiments demonstrated that B4GALNT3 suppresses NB cell proliferation, migration, and invasion primarily by increasing LacdiNAc modification of $\beta 1$ integrin, thereby inhibiting the downstream signaling of $\beta 1$ integrin (Table 1) [81]. However, in human colon cancers, our research team previously presented that

Table 1 Glycosyltransferases as prognostic markers with differential effects on neuroblastoma and other cancers

\begin{tabular}{|c|c|c|c|}
\hline Enzymes & $\begin{array}{l}\text { Glycosylation } \\
\text { involved }\end{array}$ & Target proteins and associated signaling pathways & Clinical significance \\
\hline $\begin{array}{l}\text { B1,3-N-acetylglucosaminyltransferase } \\
3 \text { (B3GNT3) }\end{array}$ & O-glycosylation & $\begin{array}{l}\text { B3GNT3 inhibits NB cell migration and invasion by } \\
\text { suppression of FAK, Akt, and ERK activation. }\end{array}$ & $\begin{array}{l}\text { Predicts good prognosis } \\
\text { in NB [78]. }\end{array}$ \\
\hline $\begin{array}{l}\text { B1,4-N-acetylgalactosaminyltransferase } \\
3 \text { (B4GALNT3) }\end{array}$ & $\begin{array}{l}\mathrm{N} \text { - and } \mathrm{O}- \\
\text { glycosylation }\end{array}$ & $\begin{array}{l}\text { B4GALNT3 inhibits NB cell migration and invasion by } \\
\text { modifying } \beta 1 \text { integrin with LacdiNAc, thereby suppresses } \\
\text { the activation of Akt and ERK signaling pathways. } \\
\text { B4GALNT3 enhances the stemness, migration, and invasion } \\
\text { by modifying primarily N-glycans with LacdiNAc on EGFR } \\
\text { and downstream signaling in CRC cells. }\end{array}$ & $\begin{array}{l}\text { Predicts good prognosis } \\
\text { in NB [81]. } \\
\text { Predicts poor prognosis } \\
\text { in CRC [83]. }\end{array}$ \\
\hline $\begin{array}{l}\text { B1,4-galactosyltransferase } \\
3 \text { (B4GALT3) }\end{array}$ & $\begin{array}{l}\mathrm{N} \text { - and } \mathrm{O}- \\
\text { glycosylation }\end{array}$ & $\begin{array}{l}\text { B4GALT3 increases NB cell migration and invasion by } \\
\text { modifying lactosamine structures of } \beta 1 \text { integrin, delaying } \\
\text { the degradation of } \beta 1 \text { integrin, and enhancing its } \\
\text { downstream signaling. } \\
\text { B4GALT3 suppresses CRC cell migration and invasion by } \\
\text { inhibiting } \beta 1 \text { integrin activation through altering the } \\
\text { poly- } N \text {-acetyllactosamine expression on } N \text {-glycans of } \beta 1 \\
\text { integrin. }\end{array}$ & $\begin{array}{l}\text { Predicts poor prognosis } \\
\text { in NB [86]. } \\
\text { Predicts good prognosis } \\
\text { in CRC [87]. }\end{array}$ \\
\hline $\begin{array}{l}\text { N-acetylgalactosaminyltransferase } \\
2 \text { (GALNT2) }\end{array}$ & O-glycosylation & $\begin{array}{l}\text { GALNT2 regulates NB cell growth, migration, and invasion } \\
\text { by modifying O-glycans on IGF-1R, thereby suppressing } \\
\text { IGF-1-induced IGF-1R dimerization and downstream signaling. } \\
\text { GALNT2 inhibites HCC cell proliferation, migration, and } \\
\text { invasion by modifying O-glycans on EGFR, thereby suppressing } \\
\text { EGF-induced endocytosis of EGFR and downstream signaling. } \\
\text { GALNT2 enhances OSCC cell migration and invasion by } \\
\text { modifying O-glycosylation and activity of EGFR. }\end{array}$ & $\begin{array}{l}\text { Predicts good prognosis } \\
\text { in NB [90]. } \\
\text { Predicts good prognosis } \\
\text { in HCC [91]. } \\
\text { Predicts poor prognosis } \\
\text { OSCC [92]. }\end{array}$ \\
\hline $\begin{array}{l}\text { N-acetylglucosaminyltransferase } \\
\text { V (GnT-V; MGAT5) }\end{array}$ & N-glycosylation & $\begin{array}{l}\text { GnT-V knockdown results in a decrease in the susceptibility } \\
\text { to cell apoptosis induced by retinoic acid in NB cells } \\
\text { accompanied by morphological change }\end{array}$ & $\begin{array}{l}\text { Predicts good prognosis } \\
\text { in NB [38]. }\end{array}$ \\
\hline
\end{tabular}


B4GALNT3 messenger RNA (mRNA) is frequently up-regulated in primary colon cancer tumors compared with their normal counterparts. B4GALNT3 overexpression significantly promotes malignant behaviors of colon cancer cells both in vitro and in vivo through enhanced mitogen-activated protein kinase (MAPK) signaling pathways [82]. We later found that B4GALNT3 expression examined using IHC staining correlates positively with advanced American Joint Committee on Cancer stages, high metastasis rates, and poor survival in colorectal cancer patients. Moreover, cell line experiments revealed that B4GALNT3 expression regulates cancer stemness and the invasive properties of colon cancer cells through modifying epidermal growth factor receptor (EGFR) glycosylation and downstream signaling (Table 1) [83].

\section{$\beta 1,4-$ galactosyltransferase 3}

Another interesting glycosyltransferase, $\beta 1,4$-galactosyltransferase 3 (B4GALT3), is a member of the B4GALT family composed of seven isoenzymes and is responsible for transferring galactose from UDP-Gal to GlcNActerminated oligosaccharides on $\mathrm{N}$-glycans, $\mathrm{O}$-glycans, glycolipids, or GAG chains to form poly- $N$-acetyllactosamines (Fig. 2) [84]. B4GALT3 has been noted to have higher expression levels in fetal brains than in adult brains [85]. Our research team found that positive B4GALT3 expression examined by IHC staining in NB tumor tissues correlates negatively with the histological grade of differentiation and early clinical stage and is an unfavorable prognostic factor independent of other factors for NB patients. Moreover, B4GALT3 increases poly- $N$-acetyllactosamine levels on the mature form of $\beta 1$-integrin, which delays $\beta 1$-integrin degradation and enhances its downstream signaling, thereby increasing NB cell migration and invasion (Table 1) [86]. Our team later reported that the expression level of B4GALT3 in colorectal cancer (CRC) patients negatively correlates with poorly differentiated histology, advanced stages, and metastasis. Cell line experiments revealed that B4GALT3 overexpression inhibits CRC cell malignant phenotypes by decreasing the synthesis of poly- $N$-acetyllactosamines on $N$-glycans of $\beta 1$-integrin, which in turn suppresses its downstream signaling related to cell attachment to ECM, cell migration, and invasion (Table 1) [87].

\section{$\mathrm{N}$-acetylgalactosaminyltransferase 2}

$\mathrm{N}$-acetylgalactosaminyltransferase 2 (GALNT2), a member of the GALNT family responsible for initiation of mucin-type $O$-glycosylation (Fig. 2), has been found to express differentially in nervous tissues during mouse embryogenesis [88]. The expression of GALNT2 also regulates migration and invasion of human glioma cells in vitro [89]. In NB, we found that increased GALNT2 expression examined using IHC in primary tumor tissues correlates well with the histological grade of differentiation and early clinical stage and may serve as an independent prognostic factor for better survival of $\mathrm{NB}$ patients. In vitro and in vivo experiments using overexpression and knockdown revealed that the expression of GALNT2 suppresses IGF-1-induced cell growth, migration, and invasion of NB cells by modifying $O$-glycans on IGF-1R, which suppresses IGF-1-triggered IGF-1R dimerization and subsequent downstream signaling events (Table 1) [90]. In hepatocellular carcinoma (HCC), we observed that GALNT2 mRNA expression exhibits significant down-regulation in HCC tissues compared with normal counterparts. We also found that GALNT2 expression suppresses cell malignant phenotypes by modulating the $O$-glycosylation of EGFR, which inhibits EGF-induced endocytosis and colocalization of EGFR and its downstream signaling [91]. In oral squamous cell carcinoma (OSCC), although GALNT2 expression can also modify the $\mathrm{O}$-glycosylation of EGFR, it can facilitate the activation and downstream signaling of EGFR, thereby enhancing OSCC cell migration and invasion (Table 1) [92].

\section{Glycosyltransferases may serve as biomarkers for NB}

From the series of studies above, it is postulated that different cell types possess differential expression patterns (repertoire) of isoenzymes, which may result in different glycosylation sites or densities of cell-surface receptors [93]. GALNT2, for example, may add GalNAc to different $O$-glycosites on EGFR in HCC and OSCC cells, which is determined by the repertoire of GALNTs in respective cells. Therefore, EGFR glycoforms modulated differentially by GALNT2 in these cells may present with opposite cellular properties, including cell proliferation, growth, oncogenesis, and metastasis. Moreover, differential sialylation patterns of shorter glycans (such as sTn, sLe $\mathrm{e}^{\mathrm{a} / \mathrm{x}}$, or di-sLe ${ }^{\mathrm{a} / \mathrm{x}}$ ) regulated by sialyltransferases are also attributed to specific glycoforms at the cell surface of these cancers.

Taken together, these enzymes could be potential candidates for a panel of tumor markers for MRD detection or treatment outcome of NB patients, yet the significance of individual enzymes and more detailed molecular mechanisms need further investigation. They will help to define and develop personalized treatment for patients with NB. Moreover, they may provide an alternative approach to cancer therapy by means of modulating cancer-specific glycosylation.

\section{The roles of Gal-1 and CD44 in NB microenvironment}

Soluble Gal-1 has been found to be secreted by different NB cell lines and was identified as a major mediator of 
TrkB-mediated NB aggressiveness [6]. Additionally, NBderived Gal-1 may dampen the function of $\mathrm{T}$ cells and dendritic cells [94]. Gal-1 may also mediate attachment of cancer cells to the ECM and endothelial cells through binding to CD44 (Fig. 3) [95].

CD44, a complex transmembrane glycoprotein, was found to be closely associated with the development of various solid tumors in terms of cancer stemness and epithelial-mesenchymal transition (EMT) [60]. However, CD44 is generally downregulated in human NB cells [96]. Unlike other cancers, the absence of CD44 expression indicates aggressiveness and poor clinical outcome in NB [97]. One of the CD44 isoforms, CD44v6, contains sequences encoded by variant exon v6. CD44v6 serves as the carrier of $\mathrm{T}$ and $\mathrm{sTn}$ antigens in colon cancer cells and has been linked to metastatic spreading of a number of malignancies [60]. In NB, the induction of $\mathrm{CD} 44 \mathrm{~V}$ isoform (especially CD44v6) expression by 12-O-tetradecanoyl phorbol-13-acetate (TPA), IGF-1, and PDGF was correlated with an increased cellular binding to hyaluronic acid (a major counterreceptor for CD44; free form of GAGs in ECM) by phosphoinositide 3-kinase (PI3K)/protein kinase C (PKC) pathways, indicating the impact of glycosylation status and local distributions of the molecule on the changes in NB cell properties (Fig. 3) [98]. The interactions between Gal-1, CD44, and other associated molecules have made them become interesting therapeutic targets and/or prognostic factors for patients with NB.

\section{Disialoganglioside expression and therapeutic applications in NB}

In normal human tissues, GD2 is a surface glycolipid antigen expressed on neurons, skin melanocytes, and peripheral sensory nerve fibers. In NB, GD2 (synthesized by the GD2 synthase) is uniformly expressed by virtually all neuroblasts and is involved in the attachment of NB cells to ECM proteins (Fig. 3) [20]. This feature makes GD2 potentially suitable for a molecular marker for residual disease (but not a prognostic marker) and a target for immunotherapy. Although the use of isotretinoin (13-cis-retinoid acid) has been incorporated into the standard treatment as a biotherapy for high-risk NB patients, monoclonal antibodies directed against NB-specific antigens such as GD2 may provide another efficacious approach to eliminate residual NB cells by complement-dependent cytotoxicity (CDC) and antibodydependent cell-mediated cytotoxicity (ADCC). There are four major anti-GD2 monoclonal antibodies (mAbs) (3F8, hu3F8, ch14.18, and hu14.18) being extensively tested in clinical settings [12]. A phase III randomized study reported by $\mathrm{Yu}$ et al. showed that adding immunotherapy (ch14.18 in combination with granulocyte-macrophage colony-stimulating factor (GM-CSF) and interleukin
(IL)-2 to enhance the ADCC) to isotretinoin therapy, as compared with the use of isotretinoin alone, improved the survival of children with high-risk NB in remission after myeloablative therapy and stem-cell rescue [99]. A recent study even suggests that autologous stem-cell transplantation may not be needed to improve outcome when anti-GD2 immunotherapy is used for consolidation after dose-intensive conventional chemotherapy [100]. Further clinical investigations of several novel combinatorial immunotherapies are underway and will provide new hope for infants and children with NB.

\section{Conclusions}

\section{Glycan-based therapeutics in cancers}

The presence of glycans on various biomolecules shows their physiological and pathological importance; therefore, glycan-based therapeutics has been developed for treatment of cancers and other diseases, such as glycosyltransferase inhibitors, glycomimetics, glycan/glycopeptide vaccines, antibody therapies, and antibody-based immunotherapies. Sialic acid and fucose are the common glycan structures on the terminal branches of $\mathrm{N}$ - and $\mathrm{O}$-glycans of glycoproteins and are involved in cancer progression and metastasis. It has been reported that the cell-permeable, fluorinated analogs of fucose and sialic acid can be used as inhibitors of both fucosyltransferases and sialyltransferases and drastically reduced sLe $\mathrm{e}^{\mathrm{x}}$ expression on myeloid cells, resulting in loss of binding to selectins and impaired leukocyte rolling [101]. Several other inhibitors that target sialyltransferases have been developed, such as soyasaponin-I (selectively inhibits $\alpha 2,3$-sialyltransferases activity) and AL10 (inhibits $\alpha 2,3-$ and $\alpha 2,6$-sialyltransferases activity), for treatment of metastatic breast and lung cancer cells, respectively [13, 14]. Glycomimetic drugs such as acetylated or/and fluorinated derivatives of glycans (4F-GalNAc and 4F-GlcNAc) were used as decoys to disrupt the biosynthesis of natural ligands for selectins, which blocked selectin interaction with the endogenous glycans and mediated cellular adhesion [102]. These studies may pave the way for the broader use of these glycosyltransferase inhibitors or glycomimetics in NB patients. However, because all members of a given family utilize the same donor substrate (such as GlcNAc for B3GNT3, GalNAc for B4GALNT3 or GALNTs), the differential cellular expression pattern and acceptor specificity of each enzyme in NB cells need to be clarified further in the future..

Unusual glycomotifs on glycoproteins can be recognized by the immune system, but they are weak immunogens. Therefore, vaccines of this type are typically prepared by conjugating the glycan to a carrier protein to boost both humoral and cellular immune responses, such as the use of sTn-KLH vaccines in phase III clinical 
trials for breast cancer patients with metastatic disease [103]. Other glycan/glycopeptide vaccines have been designed and generated to elicit more robust immune responses, such as the development of synthetic vaccines consisting of a MUC1 glycopeptide along with a T helper (Th) peptide [104], a MUC1 glycopeptide along with toll-like receptor 2 (TLR2) lipopeptide ligands [105] or a MUC1 glycopeptide along with a Th peptide and a TLR2/TLR9 agonist [106]. Multivalent vaccines targeting multiple mucins have been developing against various cancers [22]. To date, advances in availability of recombinant glycosyltransferases have made it possible to synthesize cancer-associated antigens mimicking the surface of cancer cells in terms of glycosylation sites and density, which allows for specific targeting cancer cells with immunotherapeutics [22].

NB-associated glycoforms provide information with which cancer vaccines are designed and synthesized. For example, a phase I trial of a bivalent GD2-GD3 gangliosides vaccine in combination with the immunostimulant $\beta$-glucan revealed an encouraging result in high-risk NB patients [107]. Another vaccine target used for NB is $N$ glycolyl GM3 (NeuGcGM3), which is expressed in $85 \%$ of NB cases, including those with $M Y C N$ amplification [108]. Racotumomab is a murine anti-idiotype vaccine that mimics NeuGcGM3 and was reported to trigger an anti-NeuGcGM3 response in adults with melanomas [15], lung cancers [16], and breast cancers [17]. A phase I study using racotumomab in children with $\mathrm{NB}$ and other refractory malignancies revealed that most patients elicited an immune response against racotumomab but did not show significant anti-tumor activity in most cohort patients who were heavily pre-treated with front-line therapy. Therefore, evaluation of long-term vaccination with this vaccine is underway [109].

\section{Perspectives on glycosylation-based therapies for NB}

It is well-known that receptor kinases that mediate arrest and differentiation tend to have low multiplicity, and their dependency on $\mathrm{N}$-glycan branching or $\mathrm{O}$-glycosylation for surface residency is altered by oncogenesis-driven membrane remodeling. We reason that "nontransformed" dynamics can be restored by jointly manipulating protein synthesis, $\mathrm{N}$ - or $\mathrm{O}$-glycosylation, and Golgi remodeling to change the cell-surface glycosylation pattern involved in growth and arrest [34]. Moreover, epigenetic mechanisms on glycogenes (e.g., DNA methylation, histone modifications, and non-coding RNAs [110-117]) (Table 2) associated with cell-surface glycosylation in various cancers may develop as potential targets for anti-tumor therapy in the near future.

So far, almost all approved $\mathrm{mAbs}$ are targeting protein antigens, except anti-GD2 mAbs. Anti-GD2 antibodies have been actively tested since 1980s in various preclinical and clinical combinatorial trials for $\mathrm{NB}$, and now have proved their safety and efficacy when combined with GM-CSF and IL-2 in the treatment of high-risk NB patients. An interesting fusion protein, namely hu14.18-IL2, has been generated by fusing an IL-2 moiety to hu14.18 mAb. This fusion protein has shown superior anti-tumor activity as compared with ch14.18 mAb combined with IL-2 in NB patients with nonbulky disease [118]. Building on the success of ch14.18, researchers are using $\mathrm{T}$ cells, engineered to express a new class of proteins known as chimeric antigen receptors (CARs), to enhance anti-tumor efficacy. Therefore, engineered human $\mathrm{T}$ lymphocytes expressing GD2-directed CARs (GD2-CARs) were generated. Louis et al. found that these GD2-CAR $\mathrm{T}$ cells can induce complete tumor responses in patients with active NB and have extended, low-level persistence associated with longer survival outcome in these patients [119].

Many approaches have been developed to improve the efficacy of therapeutic antibodies; Potelligent Technology is one of the most potent technologies for enhancing ADCC [120]. The concept of this technology originated from the discovery that reducing or eliminating fucose from the oligosaccharides on the Fc domain significantly increased FcyRIIIa binding and dramatically enhanced ADCC by $~ 100$-fold [121]. In addition, an antibody without fucose is a natural component of human serum and therefore has a lower risk of immunogenicity. A defucosylated anti-CC chemokine receptor 4 (CCR4), mogamulizumab, not only induces ADCC against CCR4 ${ }^{+}$ malignant $\mathrm{T}$ cells but also reduces $\mathrm{CCR} 4^{+}$regulatory $\mathrm{T}$ cells (Tregs) which in turn restores NK cell anti-tumor function in patients with cutaneous $\mathrm{T}$ cell lymphoma (CTCL) [18]. This drug was approved in Japan for CCR4positive adult T cell leukemia/lymphoma (ATL) in 2012 [19], relapse/refractory CCR4-positive peripheral $\mathrm{T}$ cell lymphoma (PTCL) and CTCL in 2014. Another form of defucosylated antibody, nivolumab, is a programmed death-1 (PD-1) immune-checkpoint inhibitor. PD-1 is a key immune-checkpoint receptor expressed by activated $\mathrm{T}$ cells and mediates immunosuppression. Blockade of the interaction between PD-1 (on activated T cells) and PD-L1 (PD-1 ligands; expressed on tumor cells or stromal cells) can enhance $\mathrm{T}$ cell activity and anti-tumor activity [122]. Nivolumab is approved to be used alone or with other drugs to treat metastatic melanoma, non-small cell lung cancer, and renal cell carcinoma. Anti-GD2 mAb in combination with anti-PD-1 mAb has been added to the present treatment protocols for high-risk NB and is likely to be studied in the future $[123,124]$. The mutated humanized antibody, hu14.18K322A (lysine to alanine in the $\mathrm{CH} 2$ region critical for complement activation) produced by YB2/0 cells, showed decreased fucosylation activity and demonstrated increased ADCC and less complement 
Table 2 Identified glycogene/miRNA interactions in human diseases

\begin{tabular}{|c|c|c|}
\hline miRNAs & Glycogene targets & Comments \\
\hline miR-30b/30d & GALNT1, GALNT7 & $\begin{array}{l}\text { Both GALNT1 and GALNT7 are targets of miR-30b/d, which are associated } \\
\text { with metastasis in melanoma [112]. }\end{array}$ \\
\hline miR-378 & GALNT7 & $\begin{array}{l}\text { GALNT7 is a target of miR-378 and plays a critical role in osteoblast } \\
\text { differentiation [111]. }\end{array}$ \\
\hline miR-122 & GALNT10, FUT8 & $\begin{array}{l}\text { GALNT10 modulates O-glycosylation of EGFR in hepatitis B virus (HBV)-infected } \\
\text { hepatoma cells. GALNT10 is a target of miR-122, whose gene transcription is } \\
\text { activated by hepatocyte nuclear factor } 4 \text { a }(\mathrm{Hnf} 4 \mathrm{a}) \text {. Therefore, a regulatory pathway } \\
\text { of Hnf4a/miR-122/GALNT10/EGFR may develop as therapeutic targets [113]. } \\
\text { Ectopic expression of miR-122 can significantly decrease FUT8 levels, thus may play } \\
\text { a role in the dysregulation of core fucosylation observed in liver tumors [114]. }\end{array}$ \\
\hline miR-27a & B4GALT3 & $\begin{array}{l}\text { B4GALT3 up-regulated by miR-27a contributes to the tumorigenic activities by } \\
\text { B1-integrin pathway and might provide potential biomarkers for cervical cancer [117]. }\end{array}$ \\
\hline miR-148b & C1GALT1 & $\begin{array}{l}\text { Inhibition of miR-148b expression can reverse the lower levels of C1GALT1 typical } \\
\text { of IgA nephropathy. Therefore, miR-148b levels may be manipulated to provide a } \\
\text { therapeutic approach to the disease [110]. }\end{array}$ \\
\hline miR-199b-5p & FUT4 & $\begin{array}{l}\text { The cluster of differentiation carbohydrate antigen CD15, also known as FUT4, is a } \\
\text { marker of medulloblastoma tumor-propagating cells and an additional direct target } \\
\text { of miR-199b-5p. Therefore, the finely tuned regulation of miR-199b-5p may have a } \\
\text { role in therapeutic application in medulloblastoma [115]. }\end{array}$ \\
\hline miR-34a & FUT8 & $\begin{array}{l}\text { Ectopic expression of miR-34a can significantly decrease FUT8 levels, thus may play } \\
\text { a role in the dysregulation of core fucosylation observed in liver tumors [114]. }\end{array}$ \\
\hline miR-125b & ERManl & $\begin{array}{l}\text { ERManl functions as a "gate keeper" in the Golgi complex to facilitate the retention } \\
\text { and recycling of misfolded glycoproteins escaped from the ER. In hepatoma cells, } \\
\text { however, ERManl regulates transformation phenotypes independent of ER-stress. } \\
\text { ERManl knockdown by miR-125b inhibits proliferation and migration of hepatoma } \\
\text { cells [116]. }\end{array}$ \\
\hline
\end{tabular}

B4GALT3 $\beta 1$,4-galactosyltransferase 3, C1GALT1 core $1 \beta 1,3$-galactosyltransferase, FUT fucosyltransferase, GALNT N-acetylgalactosaminyltransferase, ERMan/ human endoplasmic reticulum alpha-1, 2-mannosidase I

activation (which was related to hypersensitivity reactions) than ch14.18. Therefore, this antibody has the potential to be less toxic, allowing for higher maximum tolerated dose (MTD) and improved efficacy for refractory/recurrent NB patients [125].

\section{Where do we go from here?}

Recent advances in cancer cell glycomics have expanded the armamentarium of NB therapeutic targets. However, treatment of high-risk $\mathrm{NB}$ is still challenging because $\sim 40 \%$ of patients still relapse during or after glycan-based immunotherapy following standard therapy [99]. In the last two decades, several anti-GD2 antibodies and GD2-GD3 vaccines have been developed and tested in clinical trials, resulting in various treatment responses. Development of an immune response is always a concern with genetically engineered mAbs, such as human anti-mouse antibodies (HAMA), human anti-human antibodies (HAHA), or anti-chimeric-antibodies, which may influence the level of antibody therapy and potentially contribute to the undesirable adverse effects [126, 127]. Maintaining anti-tumor antibodies over months or years is more readily achievable with vaccines than with mAbs. However, Kushner et al. postulated that fluctuations in anti-GD2 titers in vaccinated patients may represent multiple idiotypes within an idiotypic network [107]. Nevertheless, these results support the idea of using GD2-GD3 vaccine as an adjuvant therapy in patients with low disease burdens but at high risk for relapse and with target antigens highly expressed in cancerous tissues but not normal tissues, after these patients have completed the standard upfront multimodal treatments [107].

In conclusion, aberrant protein glycosylation in tumor cells and NB microenvironment provides clinicians with additional opportunities to screen for specific glycosyltransferase inhibitors, glycomimetics, and glycan-based vaccines/immunotherapies. This feature also allows the development of novel genetically and epigenetically based therapies. Further investigation of the intricate glycoforms on NB cells may lead to the identification of more useful prognostic, diagnostic, and therapeutic targets in the future.

\footnotetext{
Abbreviations

ADCC: Antibody-dependent cell-mediated cytotoxicity; ALK: Anaplastic lymphoma kinase; ATL: Adult T cell leukemia/lymphoma; B3GNT3: $\beta 1,3-N$ acetylglucosaminyltransferase 3; B3GNT6: $\beta 1,3-N$ -

acetylglucosaminyltransferase 6; B4GALNT3: $\beta 1,4-N$ -

acetylgalactosaminyltransferase 3; B4GALT3: $\beta 1$,4-galactosyltransferase 3; C1GALT1: Core 1 1,3-galactosyltransferase; CARs: Chimeric antigen receptors; CCR4: CC chemokine receptor 4; CDC: Complement-dependent cytotoxicity; CRC: Colorectal cancer; CTCL: Cutaneous T cell lymphoma; ECM: Extracellular matrix; EGF: Epidermal growth factor; EGFR: Epidermal growth factor receptor; EMT: Epithelial-mesenchymal transition; ER: Endoplasmic reticulum; GAGs: Glycosaminoglycans; Gal-1: Galectin-1;
} 
GalNAc: N-acetylgalactosamine; GALNT: N-acetylgalactosaminyltransferase; GBP: Glycan-binding protein; GCNT: $\beta 1,6-N$-acetylglucosaminyltransferase: GD2: Disialoganglioside; GICNAc: N-acetylglucosamine; GM-CSF: Granulocytemacrophage colony-stimulating factor; GnT: $\beta 1,6-N-$

acetylglucosaminyltransferase; GPI: Glycosylphosphatidylinositol; HAHA: Human anti-human antibodies; HAMA: Human anti-mouse antibodies; HCC: Hepatocellular carcinoma; HEVs: High endothelial venules; ICAM2: Intercellular adhesion molecule-2; IGF: Insulin-like growth factor; IHC: Immunohistochemistry; IL-2: Interleukin-2; INSS: International neuroblastoma staging system; LDN: LacdiNAc or GalNAc $\beta 1,4 G \mid c N A c$; mAbs: Monoclonal antibodies; MAPK: Mitogen-activated protein kinase; MGAT: $\beta 1,6-N$-acetylglucosaminyltransferase; MRD: Minimal residual disease; MTD: Maximum tolerated dose; MUC: Mucin; MYCN: V-myc myelocytomatosis viral-related oncogene; NeuGcGM3: N-glycolyl GM3; OSCC: Oral squamous cell carcinoma; PD-1: Programmed death-1; PDGF: Platelet-derived growth factor; PD-L1: PD-1 ligands; PI3K: Phosphoinositide 3-kinase; PKC: Protein kinase C; PTCL: Peripheral T cell lymphoma; sLe ${ }^{a}$ : Sialyl-Lewis A; sLe ${ }^{x}$ : Sialyl-Lewis X; ST3Gal: Gal:2,3sialyltransferase; ST6Gal-I: Gal: a2,6-sialyltransferase-l; ST6GalNAc: GalNAc:2,6sialyltransferase; sTn: Sialyl-Tn; T: Thomsen-Friedenreich; TGF: Transforming growth factor; Th: T helper; TLR: Toll-like receptor; Tn: Thomsen-nouvelle; TPA: 12-O-tetradecanoyl phorbol-13-acetate; Tregs: Regulatory T cells

\section{Acknowledgements}

Not applicable.

\section{Funding}

This work was supported by Ministry of Science and Technology, R.O.C. (MOST 103-2314-B-341-005 to Dr. Wan-Ling Ho; NSC 99-2628-B-002-056-MY3 and NSC 102-2628-B-002-031-MY2 to Dr. Wen-Ming Hsu; MOST 104-2320-B-002-068-MY3 to Dr. Min-Chuan Huang), National Taiwan University (NTU.101-R7808 to Dr. Min-Chuan Huang), National Taiwan University Hospital (NTUH-101-S1787 and NTUH-103-S2388 to Dr. Wen-Ming Hsu), Japan Science and Technology Agency, Core Research for Evolutionary Science and Technology (JST CREST) (to Dr. Kenji Kadomatsu), and Japan Agency for Medical Research and Development (AMED) (Tailor-made Medical Treatment Program) (to Dr. Kenji Kadomatsu).

\section{Availability of data and materials}

Not applicable.

\section{Authors' contributions}

WLH performed the literature search and wrote the manuscript. WMH, MCH, $\mathrm{KK}$, and $\mathrm{AN}$ read and approved the final manuscript. WMH and $\mathrm{MCH}$ contributed equally to this work. All authors read and approved the final manuscript.

\section{Competing interests}

The authors declare that they have no competing interests.

\section{Consent for publication}

Not applicable.

\section{Ethics approval and consent to participate}

Not applicable.

\begin{abstract}
Author details
${ }^{1}$ School of Medicine, College of Medicine, Fu Jen Catholic University, New Taipei 24205, Taiwan. ${ }^{2}$ Department of Pediatrics, Shin Kong Wu Ho-Su Memorial Hospital, Taipei, Taiwan. ${ }^{3}$ Department of Pediatrics, National Taiwan University Hospital, Taipei, Taiwan. ${ }^{4}$ Department of Surgery, National Taiwan University Hospital, 7 Chung-Shan South Road, Taipei 100, Taiwan. ${ }^{5}$ Research Center for Developmental Biology and Regenerative Medicine, National Taiwan University, Taipei, Taiwan. ${ }^{6}$ Graduate Institute of Anatomy and Cell Biology, College of Medicine, National Taiwan University, No. 1, Sec. 1, Jen-Ai Road, Taipei 10051, Taiwan. ${ }^{7}$ Department of Biochemistry, Nagoya University Graduate School of Medicine, Nagoya, Japan. ${ }^{8}$ Saga Medical Center Koseikan, Saga, Japan.
\end{abstract}

Received: 30 June 2016 Accepted: 23 September 2016 Published online: 29 September 2016

\section{References}

1. Fuster MM, Esko JD. The sweet and sour of cancer: glycans as novel therapeutic targets. Nat Rev Cancer. 2005;5(7):526-42.

2. Weis WI, Drickamer K. Structural basis of lectin-carbohydrate recognition. Annu Rev Biochem. 1996;65:441-73.

3. Banh A, Zhang J, Cao H, Bouley DM, Kwok S, Kong C, et al. Tumor galectin-1 mediates tumor growth and metastasis through regulation of T-cell apoptosis. Cancer Res. 2011;71(13):4423-31.

4. Tang D, Yuan Z, Xue X, Lu Z, Zhang Y, Wang H, et al. High expression of galectin-1 in pancreatic stellate cells plays a role in the development and maintenance of an immunosuppressive microenvironment in pancreatic cancer. Int J Cancer. 2012;130(10):2337-48.

5. Miyazaki K, Sakuma K, Kawamura Yl, Izawa M, Ohmori K, Mitsuki M, et al. Colonic epithelial cells express specific ligands for mucosal macrophage immunosuppressive receptors siglec-7 and -9. J Immunol. 2012;188(9):4690-700.

6. Cimmino F, Schulte JH, Zollo M, Koster J, Versteeg R, lolascon A, et al. Galectin-1 is a major effector of TrkB-mediated neuroblastoma aggressiveness. Oncogene. 2009;28(19):2015-23.

7. Kamijo T, Nakagawara A. Molecular and genetic bases of neuroblastoma. Int J Clin Oncol. 2012;17(3):190-5.

8. Liu YL, Miser JS, Hsu WM. Risk-directed therapy and research in neuroblastoma. J Formos Med Assoc. 2014;113(12):887-9.

9. Liu YL, Lo WC, Chiang CJ, Yang YW, Lu MY, Hsu WM, et al. Incidence of cancer in children aged 0-14 years in Taiwan, 1996-2010. Cancer Epidemiol. 2015;39(1):21-8

10. Brodeur GM, Pritchard J, Berthold F, Carlsen NL, Castel V, Castelberry RP, et al. Revisions of the international criteria for neuroblastoma diagnosis, staging, and response to treatment. J Clin Oncol. 1993;11(8):1466-77.

11. Castleberry RP. Neuroblastoma. Eur J Cancer. 1997;33(9):1430-7. discussion 7-8.

12. Ahmed M, Cheung NK. Engineering anti-GD2 monoclonal antibodies for cancer immunotherapy. FEBS Lett. 2014;588(2):288-97.

13. Chiang $\mathrm{CH}$, Wang $\mathrm{CH}$, Chang HC, More SV, Li WS, Hung WC. A novel sialyltransferase inhibitor AL10 suppresses invasion and metastasis of lung cancer cells by inhibiting integrin-mediated signaling. J Cell Physiol. 2010;223(2):492-9.

14. Hsu CC, Lin TW, Chang WW, Wu CY, Lo WH, Wang PH, et al. Soyasaponin-Imodified invasive behavior of cancer by changing cell surface sialic acids. Gynecol Oncol. 2005;96(2):415-22.

15. Carr A, Mazorra Z, Alonso DF, Mesa C, Valiente O, Gomez DE, et al. A purified GM3 ganglioside conjugated vaccine induces specific, adjuvantdependent and non-transient antitumour activity against B16 mouse melanoma in vitro and in vivo. Melanoma Res. 2001;11(3):219-27.

16. Alfonso S, Diaz RM, de la Torre A, Santiesteban E, Aguirre F, Perez K, et al. $1 \mathrm{E} 10$ anti-idiotype vaccine in non-small cell lung cancer: experience in stage IIIb/IV patients. Cancer Biol Ther. 2007;6(12):1847-52.

17. Diaz A, Alfonso M, Alonso R, Saurez G, Troche M, Catala M, et al. Immune responses in breast cancer patients immunized with an anti-idiotype antibody mimicking NeuGc-containing gangliosides. Clin Immunol. 2003:107(2):80-9.

18. Ni X, Jorgensen JL, Goswami M, Challagundla P, Decker WK, Kim YH, et al. Reduction of regulatory $T$ cells by mogamulizumab, a defucosylated anti-CC chemokine receptor 4 antibody, in patients with aggressive/refractory mycosis fungoides and Sezary syndrome. Clin Cancer Res. 2015;21(2):274-85.

19. Ishida T, Joh T, Uike N, Yamamoto K, Utsunomiya A, Yoshida S, et al. Defucosylated anti-CCR4 monoclonal antibody (KW-0761) for relapsed adult T-cell leukemia-lymphoma: a multicenter phase II study. J Clin Oncol. 2012;30(8):837-42

20. Cheresh DA, Pierschbacher MD, Herzig MA, Mujoo K. Disialogangliosides GD2 and GD3 are involved in the attachment of human melanoma and neuroblastoma cells to extracellular matrix proteins. J Cell Biol. 1986;102(3):688-96.

21. Helenius A, Aebi M. Intracellular functions of N-linked glycans. Science. 2001:291(5512):2364-9.

22. Tarp MA, Clausen H. Mucin-type O-glycosylation and its potential use in drug and vaccine development. Biochim Biophys Acta. 2008;1780(3):546-63.

23. Reis CA, Osorio H, Silva L, Gomes C, David L. Alterations in glycosylation as biomarkers for cancer detection. J Clin Pathol. 2010:63(4):322-9.

24. Tian E, Ten Hagen KG. Recent insights into the biological roles of mucintype O-glycosylation. Glycoconj J. 2009;26(3):325-34.

25. Ten Hagen KG, Fritz TA, Tabak LA. All in the family: the UDP-GalNAc: polypeptide N-acetylgalactosaminyltransferases. Glycobiology. 2003;13(1):1R-16R 
26. Cao Y, Stosiek P, Springer GF, Karsten U. Thomsen-Friedenreich-related carbohydrate antigens in normal adult human tissues: a systematic and comparative study. Histochem Cell Biol. 1996;106(2):197-207.

27. Schwientek T, Nomoto M, Levery SB, Merkx G, van Kessel AG, Bennett EP, et al. Control of O-glycan branch formation. Molecular cloning of human cDNA encoding a novel beta1,6-N-acetylglucosaminyltransferase forming core 2 and core 4. J Biol Chem. 1999;274(8):4504-12.

28. Iwai T, Inaba N, Naundorf A, Zhang Y, Gotoh M, Iwasaki H, et al. Molecular cloning and characterization of a novel UDP-GlcNAc:GalNAc-peptide beta1,3-N-acetylglucosaminyltransferase (beta 3Gn-T6), an enzyme synthesizing the core 3 structure of O-glycans. J Biol Chem. 2002;277(15):12802-9.

29. Brockhausen I, Schachter H, Stanley P. O-GalNAc glycans. In: Varki A, Cummings RD, Esko JD, Freeze HH, Stanley P, Bertozzi CR, et al., editors. Essentials of glycobiology. 2nd ed. Harbor: Cold Spring; 2009.

30. Rabinovich GA, van Kooyk Y, Cobb BA. Glycobiology of immune responses. Ann N Y Acad Sci. 2012;1253:1-15.

31. Freire-de-Lima L. Sweet and sour: the impact of differential glycosylation in cancer cells undergoing epithelial-mesenchymal transition. Front Oncol. 2014:4:59.

32. Beheshti Zavareh R, Lau KS, Hurren R, Datti A, Ashline DJ, Gronda M, et al. Inhibition of the sodium/potassium ATPase impairs N-glycan expression and function. Cancer Res. 2008:68(16):6688-97.

33. Ogata SI, Muramatsu T, Kobata A. New structural characteristic of the large glycopeptides from transformed cells. Nature. 1976;259(5544):580-2.

34. Lau KS, Dennis JW. N-Glycans in cancer progression. Glycobiology. 2008;18(10):750-60.

35. Fernandes B, Sagman U, Auger M, Demetrio M, Dennis JW. Beta 1-6 branched oligosaccharides as a marker of tumor progression in human breast and colon neoplasia. Cancer Res. 1991;51(2):718-23.

36. Murata K, Miyoshi E, Kameyama M, Ishikawa O, Kabuto T, Sasaki Y, et al. Expression of $\mathrm{N}$-acetylglucosaminyltransferase $\mathrm{V}$ in colorectal cancer correlates with metastasis and poor prognosis. Clin Cancer Res. 2000;6(5):1772-7.

37. Dosaka-Akita H, Miyoshi E, Suzuki O, Itoh T, Katoh H, Taniguchi N. Expression of $\mathrm{N}$-acetylglucosaminyltransferase $\mathrm{v}$ is associated with prognosis and histology in non-small cell lung cancers. Clin Cancer Res. 2004;10(5):1773-9.

38. Inamori K, Gu J, Ohira M, Kawasaki A, Nakamura Y, Nakagawa T, et al. High expression of $\mathrm{N}$-acetylglucosaminyltransferase $\mathrm{V}$ in favorable neuroblastomas: Involvement of its effect on apoptosis. FEBS Lett. 2006;580(2):627-32.

39. Gu J, Sato Y, Kariya Y, Isaji T, Taniguchi N, Fukuda T. A mutual regulation between cell-cell adhesion and N-glycosylation: implication of the bisecting GlcNAc for biological functions. J Proteome Res. 2009;8(2):431-5.

40. Dosaka-Akita H, Kinoshita I, Yamazaki K, Izumi H, Itoh T, Katoh H, et al. Nacetylgalactosaminyl transferase-3 is a potential new marker for non-small cell lung cancers. Br J Cancer. 2002;87(7):751-5.

41. Yamamoto S, Nakamori S, Tsujie M, Takahashi Y, Nagano H, Dono K, et al. Expression of uridine diphosphate $\mathrm{N}$-acetyl-alpha-D-galactosamine: polypeptide $\mathrm{N}$-acetylgalactosaminyl transferase 3 in adenocarcinoma of the pancreas. Pathobiology. 2004;71(1):12-8.

42. Park JH, Nishidate T, Kijima K, Ohashi T, Takegawa K, Fujikane T, et al. Critical roles of mucin 1 glycosylation by transactivated polypeptide $\mathrm{N}$ acetylgalactosaminyltransferase 6 in mammary carcinogenesis. Cancer Res. 2010;70(7):2759-69.

43. Park JH, Katagiri T, Chung S, Kijima K, Nakamura Y. Polypeptide Nacetylgalactosaminyltransferase 6 disrupts mammary acinar morphogenesis through O-glycosylation of fibronectin. Neoplasia. 2011;13(4):320-6.

44. Wagner KW, Punnoose EA, Januario T, Lawrence DA, Pitti RM, Lancaster K, et al. Death-receptor O-glycosylation controls tumor-cell sensitivity to the proapoptotic ligand Apo2L/TRAIL. Nat Med. 2007;13(9):1070-7.

45. Itzkowitz SH, Yuan M, Montgomery CK, Kjeldsen T, Takahashi HK, Bigbee WL, et al. Expression of Tn, sialosyl-Tn, and T antigens in human colon cancer. Cancer Res. 1989;49(1):197-204.

46. Noguchi M, Nakajima T, Hirohashi S, Akiba T, Shimosato Y. Immunohistochemical distinction of malignant mesothelioma from pulmonary adenocarcinoma with anti-surfactant apoprotein, anti-Lewisa, and anti-Tn antibodies. Hum Pathol. 1989;20(1):53-7.

47. David L, Nesland JM, Clausen H, Carneiro F, Sobrinho-Simoes M. Simple mucin-type carbohydrate antigens (Tn, sialosyl-Tn and T) in gastric mucosa, carcinomas and metastases. APMIS Suppl. 1992;27:162-72.
48. Kaur S, Kumar S, Momi N, Sasson AR, Batra SK. Mucins in pancreatic cancer and its microenvironment. Nat Rev Gastroenterol Hepatol. 2013;10(10):607-20.

49. Schultz MJ, Swindall AF, Bellis SL. Regulation of the metastatic cell phenotype by sialylated glycans. Cancer Metastasis Rev. 2012;31(3-4):501-18.

50. Koike T, Kimura N, Miyazaki K, Yabuta T, Kumamoto K, Takenoshita S, et al. Hypoxia induces adhesion molecules on cancer cells: a missing link between Warburg effect and induction of selectin-ligand carbohydrates. Proc Natl Acad Sci U S A. 2004;101(21):8132-7.

51. Marcos NT, Bennett EP, Gomes J, Magalhaes A, Gomes C, David L, et al. ST6GalNAC-I controls expression of sialyl-Tn antigen in gastrointestinal tissues. Front Biosci (Elite Ed). 2011;3:1443-55.

52. Ju T, Lanneau GS, Gautam T, Wang Y, Xia B, Stowell SR, et al. Human tumor antigens $\mathrm{Tn}$ and sialyl $\mathrm{Tn}$ arise from mutations in Cosmc. Cancer Res. 2008;68(6):1636-46.

53. Hollingsworth MA, Swanson BJ. Mucins in cancer: protection and control of the cell surface. Nat Rev Cancer. 2004;4(1):45-60.

54. Amano M, Galvan M, He J, Baum LG. The ST6Gal I sialyltransferase selectively modifies $\mathrm{N}$-glycans on CD45 to negatively regulate galectin-1induced CD45 clustering, phosphatase modulation, and T cell death. J Bio Chem. 2003;278(9):7469-75.

55. Patnaik SK, Potvin B, Carlsson S, Sturm D, Leffler H, Stanley P. Complex Nglycans are the major ligands for galectin-1, -3 , and -8 on Chinese hamster ovary cells. Glycobiology. 2006;16(4):305-17.

56. Takenaka Y, Fukumori T, Raz A. Galectin-3 and metastasis. Glycoconj J. 2004;19(7-9):543-9.

57. Baldus SE, Monig SP, Hanisch FG, Zirbes TK, Flucke U, Oelert S, et al. Comparative evaluation of the prognostic value of MUC1, MUC2, sialylLewis(a) and sialyl-Lewis(x) antigens in colorectal adenocarcinoma. Histopathology. 2002:40(5):440-9.

58. Chaturvedi P, Singh AP, Batra SK. Structure, evolution, and biology of the MUC4 mucin. FASEB J. 2008;22(4):966-81.

59. Chen SH, Dallas MR, Balzer EM, Konstantopoulos K. Mucin 16 is a functional selectin ligand on pancreatic cancer cells. FASEB J. 2012;26(3):1349-59.

60. Singh R, Campbell BJ, Yu LG, Fernig DG, Milton JD, Goodlad RA, et al. Cell surface-expressed Thomsen-Friedenreich antigen in colon cancer is predominantly carried on high molecular weight splice variants of CD44. Glycobiology. 2001;11(7):587-92.

61. Hauselmann I, Borsig L. Altered tumor-cell glycosylation promotes metastasis. Front Oncol. 2014;4:28.

62. Krause T, Turner GA. Are selectins involved in metastasis? Clin Exp Metastasis. 1999;17(3):183-92.

63. Yoon KJ, Phelps DA, Bush RA, Remack JS, Billups CA, Khoury JD. ICAM-2 expression mediates a membrane-actin link, confers a nonmetastatic phenotype and reflects favorable tumor stage or histology in neuroblastoma. PLoS One. 2008;3(11), e3629.

64. Feduska JM, Garcia PL, Brennan SB, Bu S, Council LN, Yoon KJ. Nglycosylation of ICAM-2 is required for ICAM-2-mediated complete suppression of metastatic potential of SK-N-AS neuroblastoma cells. BMC Cancer. 2013;13:261.

65. Passoni L, Longo L, Collini P, Coluccia AM, Bozzi F, Podda M, et al. Mutationindependent anaplastic lymphoma kinase overexpression in poor prognosis neuroblastoma patients. Cancer Res. 2009;69(18):7338-46.

66. Schleiermacher G, Javanmardi N, Bernard V, Leroy Q, Cappo J, Rio Frio T, et al. Emergence of new ALK mutations at relapse of neuroblastoma. J Clin Oncol. 2014:32(25):2727-34.

67. Del Grosso F, De Mariano M, Passoni L, Luksch R, Tonini GP, Longo L. Inhibition of N-linked glycosylation impairs ALK phosphorylation and disrupts prosurvival signaling in neuroblastoma cell lines. BMC Cancer. 2011;11:525.

68. Siaw JT, Wan H, Pfeifer K, Rivera VM, Guan J, Palmer RH, et al. Brigatinib, an anaplastic lymphoma kinase inhibitor, abrogates activity and growth in ALK-positive neuroblastoma cells, Drosophila and mice. Oncotarget. 2016;7(20):29011-22.

69. Iragavarapu C, Mustafa M, Akinleye A, Furqan M, Mittal V, Cang S, et al. Novel ALK inhibitors in clinical use and development. J Hematol Oncol. 2015;8:17.

70. Zhang Y, Iwasaki H, Wang H, Kudo T, Kalka TB, Hennet T, et al. Cloning and characterization of a new human UDP-N-acetyl-alpha-D-galactosamine: polypeptide N-acetylgalactosaminyltransferase, designated pp-GalNAc-T13, that is specifically expressed in neurons and synthesizes GalNAc alphaserine/threonine antigen. J Biol Chem. 2003;278(1):573-84.

71. Berois N, Blanc E, Ripoche H, Mergui X, Trajtenberg F, Cantais S, et al. ppGalNAc-T13: a new molecular marker of bone marrow involvement in neuroblastoma. Clin Chem. 2006;52(9):1701-12. 
72. Ferrandis E, Da Silva J, Riou G, Benard I. Coactivation of the MDR1 and MYCN genes in human neuroblastoma cells during the metastatic process in the nude mouse. Cancer Res. 1994;54(8):2256-61.

73. Berois N, Gattolliat CH, Barrios E, Capandeguy L, Douc-Rasy S, ValteauCouanet D, et al. GALNT9 gene expression is a prognostic marker in neuroblastoma patients. Clin Chem. 2013;59(1):225-33.

74. Mitoma J, Petryniak B, Hiraoka N, Yeh JC, Lowe JB, Fukuda M. Extended core 1 and core 2 branched O-glycans differentially modulate sialyl Lewis X-type L-selectin ligand activity. J Biol Chem. 2003;278(11):9953-61.

75. Yeh JC, Hiraoka N, Petryniak B, Nakayama J, Ellies LG, Rabuka D, et al. Novel sulfated lymphocyte homing receptors and their control by a Core 1 extension beta 1,3-N-acetylglucosaminyltransferase. Cell. 2001;105(7):957-69.

76. Cerhan JR, Ansell SM, Fredericksen ZS, Kay NE, Liebow M, Call TG, et al. Genetic variation in 1253 immune and inflammation genes and risk of non-Hodgkin lymphoma. Blood. 2007;110(13):4455-63.

77. He M, Wu C, Xu J, Guo H, Yang H, Zhang X, et al. A genome wide association study of genetic loci that influence tumour biomarkers cancer antigen 19-9, carcinoembryonic antigen and alpha fetoprotein and their associations with cancer risk. Gut. 2014;63(1):143-51.

78. Ho WL, Che Ml, Chou CH, Chang HH, Jeng YM, Hsu WM, et al. B3GNT3 expression suppresses cell migration and invasion and predicts favorable outcomes in neuroblastoma. Cancer Sci. 2013;104(12):1600-8.

79. Sato T, Gotoh M, Kiyohara K, Kameyama A, Kubota T, Kikuchi N, et al. Molecular cloning and characterization of a novel human beta 1,4-Nacetylgalactosaminyltransferase, beta 4GalNAc-T3, responsible for the synthesis of N, N'-diacetyllactosediamine, galNAc beta 1-4GIcNAc. J Biol Chem. 2003:278(48):47534-44.

80. Fiete D, Mi Y, Oats EL, Beranek MC, Baenziger JU. N-linked oligosaccharides on the low density lipoprotein receptor homolog SorLA/LR11 are modified with terminal GalNAC-4-SO4 in kidney and brain. J Biol Chem. 2007;282(3):1873-81.

81. Hsu WM, Che Ml, Liao YF, Chang HH, Chen CH, Huang YM, et al. B4GALNT3 expression predicts a favorable prognosis and suppresses cell migration and invasion via beta(1) integrin signaling in neuroblastoma. Am J Pathol. 2011;179(3):1394-404.

82. Huang J, Liang JT, Huang HC, Shen TL, Chen HY, Lin NY, et al. Beta1,4-Nacetylgalactosaminyltransferase III enhances malignant phenotypes of colon cancer cells. Mol Cancer Res. 2007:5(6):543-52.

83. Che Ml, Huang J, Hung JS, Lin YC, Huang MJ, Lai HS, et al. beta1, 4-Nacetylgalactosaminyltransferase III modulates cancer stemness through EGFR signaling pathway in colon cancer cells. Oncotarget. 2014:5(11):3673-84.

84. Guo S, Sato T, Shirane K, Furukawa K. Galactosylation of N-linked oligosaccharides by human beta-1,4-galactosyltransferases I, II, III, IV, V, and VI expressed in Sf-9 cells. Glycobiology. 2001;11(10):813-20.

85. Almeida R, Amado M, David L, Levery SB, Holmes EH, Merkx G, et al. A family of human beta4-galactosyltransferases. Cloning and expression of two novel UDP-galactose:beta-n-acetylglucosamine beta1, 4galactosyltransferases, beta4Gal-T2 and beta4Gal-T3. J Biol Chem. 1997;272(51):31979-91.

86. Chang $\mathrm{HH}$, Chen $\mathrm{CH}$, Chou CH, Liao YF, Huang MJ, Chen YH, et al. beta-1,4Galactosyltransferase III enhances invasive phenotypes via beta1-integrin and predicts poor prognosis in neuroblastoma. Clin Cancer Res. 2013;19(7):1705-16.

87. Chen CH, Wang SH, Liu CH, Wu YL, Wang WJ, Huang J, et al. beta-1,4Galactosyltransferase III suppresses beta1 integrin-mediated invasive phenotypes and negatively correlates with metastasis in colorectal cancer. Carcinogenesis. 2014;35(6):1258-66.

88. Kingsley PD, Hagen KG, Maltby KM, Zara J, Tabak LA. Diverse spatial expression patterns of UDP-GalNAc:polypeptide N-acetylgalactosaminyltransferase family member mRNAs during mouse development. Glycobiology. 2000;10(12):1317-23.

89. Liu J, Yang $L$, Jin $M, X u L$, Wu S. Regulation of the invasion and metastasis of human glioma cells by polypeptide $\mathrm{N}$-acetylgalactosaminyltransferase 2 . Mol Med Rep. 2011;4(6):1299-305.

90. Ho WL, Chou CH, Jeng YM, Lu MY, Yang YL, Jou ST, et al. GALNT2 suppresses malignant phenotypes through IGF-1 receptor and predicts favorable prognosis in neuroblastoma. Oncotarget. 2014;5(23):12247-59.

91. Wu YM, Liu CH, Hu RH, Huang MJ, Lee JJ, Chen $\mathrm{CH}_{\text {, et al. Mucin }}$ glycosylating enzyme GALNT2 regulates the malignant character of hepatocellular carcinoma by modifying the EGF receptor. Cancer Res. 2011;71(23):7270-9.
92. Lin MC, Huang MJ, Liu CH, Yang TL, Huang MC. GALNT2 enhances migration and invasion of oral squamous cell carcinoma by regulating EGFR glycosylation and activity. Oral Oncol. 2014;50(5):478-84.

93. Steentoft C, Vakhrushev SY, Joshi HJ, Kong Y, Vester-Christensen MB, Schjoldager KT, et al. Precision mapping of the human O-GalNAC glycoproteome through SimpleCell technology. EMBO J. 2013;32(10):1478-88.

94. Soldati R, Berger E, Zenclussen AC, Jorch G, Lode HN, Salatino M, et al. Neuroblastoma triggers an immunoevasive program involving galectin-1dependent modulation of T cell and dendritic cell compartments. Int J Cancer. 2012;131(5):1131-41.

95. Ito K, Stannard K, Gabutero E, Clark AM, Neo SY, Onturk S, et al. Galectin-1 as a potent target for cancer therapy: role in the tumor microenvironment. Cancer Metastasis Rev. 2012;31(3-4):763-78.

96. Shtivelman E, Bishop JM. Expression of CD44 is repressed in neuroblastoma cells. Mol Cell Biol. 1991;11(11):5446-53.

97. Favrot MC, Combaret V, Lasset C. CD44-a new prognostic marker for neuroblastoma. N Engl J Med. 1993;329(26):1965.

98. Fichter M, Hinrichs R, Eissner G, Scheffer B, Classen S, Ueffing M. Expression of CD44 isoforms in neuroblastoma cells is regulated by PI 3-kinase and protein kinase C. Oncogene. 1997;14(23):2817-24.

99. Yu AL, Gilman AL, Ozkaynak MF, London WB, Kreissman SG, Chen HX, et al. Anti-GD2 antibody with GM-CSF, interleukin-2, and isotretinoin for neuroblastoma. N Engl J Med. 2010;363(14):1324-34.

100. Kushner BH, Ostrovnaya I, Cheung IY, Kuk D, Modak S, Kramer K, et al. Lack of survival advantage with autologous stem-cell transplantation in high-risk neuroblastoma consolidated by anti-GD2 immunotherapy and isotretinoin. Oncotarget. 2015.

101. Rillahan CD, Antonopoulos A, Lefort CT, Sonon R, Azadi P, Ley K, et al. Global metabolic inhibitors of sialyl- and fucosyltransferases remodel the glycome. Nat Chem Biol. 2012;8(7):661-8.

102. Marathe DD, Buffone Jr A, Chandrasekaran EV, Xue J, Locke RD, Nasirikenari $M$, et al. Fluorinated per-acetylated GalNAc metabolically alters glycan structures on leukocyte PSGL-1 and reduces cell binding to selectins. Blood. 2010;115(6):1303-12.

103. Miles D, Papazisis K. Rationale for the clinical development of STn-KLH (Theratope) and anti-MUC-1 vaccines in breast cancer. Clin Breast Cancer. 2003;3 Suppl 4:S134-8

104. Westerlind U, Hobel A, Gaidzik N, Schmitt E, Kunz H. Synthetic vaccines consisting of tumor-associated MUC1 glycopeptide antigens and a T-cell epitope for the induction of a highly specific humoral immune response. Angew Chem Int Ed Engl. 2008;47(39):7551-6.

105. Cai H, Huang ZH, Shi L, Zhao YF, Kunz H, Li YM. Towards a fully synthetic MUC1-based anticancer vaccine: efficient conjugation of glycopeptides with mono-, di-, and tetravalent lipopeptides using click chemistry. Chemistry. 2011;17(23):6396-406.

106. Abdel-Aal AB, Lakshminarayanan V, Thompson P, Supekar N, Bradley JM, Wolfert MA, et al. Immune and anticancer responses elicited by fully synthetic aberrantly glycosylated MUC1 tripartite vaccines modified by a TLR2 or TLR9 agonist. Chembiochem. 2014;15(10):1508-13.

107. Kushner BH, Cheung IY, Modak S, Kramer K, Ragupathi G, Cheung NK. Phase I trial of a bivalent gangliosides vaccine in combination with beta-glucan for high-risk neuroblastoma in second or later remission. Clin Cancer Res. 2014;20(5):1375-82

108. Scursoni AM, Galluzzo L, Camarero S, Lopez J, Lubieniecki F, Sampor C, et al. Detection of $\mathrm{N}$-glycolyl GM3 ganglioside in neuroectodermal tumors by immunohistochemistry: an attractive vaccine target for aggressive pediatric cancer. Clin Dev Immunol. 2011;2011:245181.

109. Cacciavillano W, Sampor C, Venier C, Gabri MR, de Davila MT, Galluzzo ML, et al. A phase I study of the anti-idiotype vaccine racotumomab in neuroblastoma and other pediatric refractory malignancies. Pediatr Blood Cancer. 2015;62(12):2120-4

110. Serino G, Sallustio F, Cox SN, Pesce F, Schena FP. Abnormal miR-148b expression promotes aberrant glycosylation of $\lg A 1$ in $\lg A$ nephropathy. J Am Soc Nephrol. 2012;23(5):814-24.

111. Kahai S, Lee SC, Lee DY, Yang J, Li M, Wang CH, et al. MicroRNA miR-378 regulates nephronectin expression modulating osteoblast differentiation by targeting GalNT-7. PLoS One. 2009;4(10), e7535.

112. Gaziel-Sovran A, Segura MF, Di Micco R, Collins MK, Hanniford D, Vega-

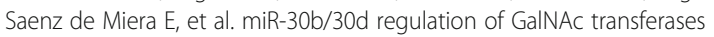
enhances invasion and immunosuppression during metastasis. Cancer Cell. 2011;20(1):104-18. 
113. Wu Q, Liu HO, Liu YD, Liu WS, Pan D, Zhang WJ, et al. Decreased expression of hepatocyte nuclear factor 4alpha (Hnf4alpha)/microRNA-122 (miR-122) axis in hepatitis B virus-associated hepatocellular carcinoma enhances potential oncogenic GALNT10 protein activity. J Biol Chem. 2015;290(2):1170-85.

114. Bernardi C, Soffientini U, Piacente F, Tonetti MG. Effects of microRNAs on fucosyltransferase 8 (FUT8) expression in hepatocarcinoma cells. PLoS One. 2013;8(10), e 76540

115. Andolfo I, Liguori L, De Antonellis P, Cusanelli E, Marinaro F, Pistollato F, et al. The micro-RNA 199b-5p regulatory circuit involves Hes 1, CD15, and epigenetic modifications in medulloblastoma. Neuro Oncol. 2012;14(5):596-612.

116. Pan S, Cheng X, Chen H, Castro PD, Ittmann MM, Hutson AW, et al. ERManl is a target of miR-125b and promotes transformation phenotypes in hepatocellular carcinoma (HCC). PLoS One. 2013;8(8), e72829.

117. Sun Y, Yang X, Liu M, Tang H. B4GALT3 up-regulation by miR-27a contributes to the oncogenic activity in human cervical cancer cells. Cancer Lett. 2016;375(2):284-92.

118. Shusterman S, London WB, Gillies SD, Hank JA, Voss SD, Seeger RC, et al. Antitumor activity of hu14.18-IL2 in patients with relapsed/refractory neuroblastoma: a Children's Oncology Group (COG) phase II study. J Clin Oncol. 2010;28(33):4969-75.

119. Louis CU, Savoldo B, Dotti G, Pule M, Yvon E, Myers GD, et al. Antitumor activity and long-term fate of chimeric antigen receptor-positive $T$ cells in patients with neuroblastoma. Blood. 2011;118(23):6050-6

120. Matsushita T. Engineered therapeutic antibodies with enhanced effector functions: clinical application of the potelligent(R) technology. Korean J Hematol. 2011:46(3):148-50.

121. Shinkawa T, Nakamura K, Yamane N, Shoji-Hosaka E, Kanda Y, Sakurada M, et al. The absence of fucose but not the presence of galactose or bisecting $\mathrm{N}$-acetylglucosamine of human IgG1 complex-type oligosaccharides shows the critical role of enhancing antibody-dependent cellular cytotoxicity. J Biol Chem. 2003;278(5):3466-73.

122. Topalian SL, Hodi FS, Brahmer JR, Gettinger SN, Smith DC, McDermott DF, et al. Safety, activity, and immune correlates of anti-PD-1 antibody in cancer. N Engl J Med. 2012;366(26):2443-54.

123. Chen R, Peng PC, Wen B, Li FY, Xie S, Chen G, et al. Anti-programmed cell death (PD)-1 immunotherapy for malignant tumor: a systematic review and meta-analysis. Transl Oncol. 2016:9(1):32-40.

124. Mackall CL, Merchant MS, Fry TJ. Immune-based therapies for childhood cancer. Nat Rev Clin Oncol. 2014;11(12):693-703.

125. Navid F, Sondel PM, Barfield R, Shulkin BL, Kaufman RA, Allay JA, et al. Phase I trial of a novel anti-GD2 monoclonal antibody, Hu14.18K322A, designed to decrease toxicity in children with refractory or recurrent neuroblastoma. J Clin Oncol. 2014;32(14):1445-52.

126. Cheung NK, Guo HF, Heller G, Cheung IY. Induction of Ab3 and Ab3' antibody was associated with long-term survival after anti-G(D2) antibody therapy of stage 4 neuroblastoma. Clin Cancer Res. 2000;6(7):2653-60.

127. Navid F, Santana VM, Barfield RC. Anti-GD2 antibody therapy for GD2expressing tumors. Curr Cancer Drug Targets. 2010;10(2):200-9.

\section{Submit your next manuscript to BioMed Central and we will help you at every step:}

- We accept pre-submission inquiries

- Our selector tool helps you to find the most relevant journal

- We provide round the clock customer support

- Convenient online submission

- Thorough peer review

- Inclusion in PubMed and all major indexing services

- Maximum visibility for your research

Submit your manuscript at www.biomedcentral.com/submit

) Biomed Central 